\title{
Phytochemical Screening, Chemical Composition and Antioxidant Activity of Leaves and Bark Extracts from Khaya senegalensis
}

\author{
Marvit Osman Widdat Allah ${ }^{1}$, Ayat Ahmed Alrasheid ${ }^{2, *}$, Altayeb Suliman Elamin ${ }^{3}$ \\ ${ }^{1}$ Department of Pharmacology, Faculty of Pharmacy, University of Medical Sciences and Technology, Khartoum, Sudan \\ ${ }^{2}$ Department of Pharmacognosy, Faculty of Pharmacy, University of Medical Sciences and Technology, Khartoum, Sudan \\ ${ }^{3}$ Department of Pharmaceutics, Faculty of Pharmacy, Omdurman Islamic University, Khartoum, Sudan
}

Email address:

marvatjazzar35@gmail.com (M. O. W. Allah), Ayatwarag@yahoo.com (A. A. Alrasheid)

${ }^{*}$ Corresponding author

\section{To cite this article:}

Marvit Osman Widdat Allah, Ayat Ahmed Alrasheid, Altayeb Suliman Elamin. Phytochemical Screening, Chemical Composition and Antioxidant Activity of Leaves and Bark Extracts from Khaya senegalensis. Advances in Biochemistry. Vol. 6, No. 4, 2018 , pp. $32-38$. doi: 10.11648/j.ab.20180604.12

Received: September 5, 2018; Accepted: September 30, 2018; Published: November 1, 2018

\begin{abstract}
Khaya senegalensis belonging to family Meliaceae. This plant has been used as traditional medicine for several disease such as pain, inflammation, malaria, anemia, diabetic and gastrointestinal diseases. The objective of this study to carry out phytochemical screening, determination of chemical composition and determine antioxidant activity of plant extracts. Many of secondary metabolites were investigated in leaves extract include alkaloids, flavonoids, sterols and saponins while the bark extract includes sterols, triterpines, tannins and saponins. The antioxidant potential of ethanol extract of leaves and bark was determined on the basis of their scavenging activity of the stable 1, 1-diphenyl-2-picryl hydrazyl (DPPH) free radical. Antioxidant activity of leaves extract was higher than bark with (42.69\%) and (36.36\%) respectively. The quantitative analysis of chemical composition was determined by Gas Chromatography-Mass Spectrometry (GC-MS). A number of bioactive compounds were present in the leaves and bark of K.senegalensis. The highest compound in both extracts represented the reducing sugar $4-\mathrm{O}-$-Methyl mannose $(66.47$ and $14.73 \%)$ in bark and leaves respectively. Fatty acids and phenols were presented in high percentage in both extract include; n-Hexadecanoic acid, 9,12,15-Octadecatrienoic acid, Oleic Acid and Catechol.
\end{abstract}

Keywords: Khaya senegalensis, Leaves, Bark, Phytochemical Screening, GC-MS Analysis, Antioxidant Activity

\section{Introduction}

Traditional medicine is the sum total of knowledge, skills and practices based on the theories, believes and experiences related to different cultures that are meant to maintain health as well as to prevent, diagnose, improve or treat physical and mental illnesses. Medicinal plants have bioactive compounds which are used for curing of various human diseases and also play an important role in healing. Phytochemicals have two categories i.e., primary and secondary constituents. Primary constituents have chlorophyll, proteins, sugar and amino acids. Secondary constituents contain many compounds such as terpenoids and alkaloids. Phytochemicals are naturally occurring in the medicinal plants leaves, vegetables, fruits, bark and roots that have defense mechanism and protect from various diseases [1]. According to the World Health Organization Traditional herbal medicines are defined as naturally occurring, plant-derived substances with minimal or no industrial processing that have been used anciently to treat illness, within local or regional healing practices [2].

Herbal medicine is also called botanical medicine or phytomedicine. The extent to which it can be used is very broad, and the medicinal properties can be achieved by using a plant's seeds, berries, roots, leaves, bark, or flowers. Herbalism has a long tradition of use outside of conventional medicine. It is becoming more mainstream as improvements in analysis and quality control along with advances in clinical 
research show the value of herbal medicine in the treating and preventing disease [2]. K.senegalensis is a tall evergreen tree which grows in the Sahara savannah area from Senegal to Uganda. The extract from the bark of K.senegalensis is characterized by its bitter constituents, is named" calicedrin" in West Africa. It is used extensively as a bittertonic for the treatment of a variety of pro-inflammatory disease. Commonly used in African traditional medicine for pain and inflammation [3]. The main chemical groups in K.senegalensis are fatty acids, carotenoids, coumarins, emodols, tannins, compounds reducers, anthracenosides, steroidal glycosides, flavonosides, carbohydrates, saponins, sterols and triterpenes, limonoids, anthocyanins, mono- and polysaccharides, mucilages and cardiac glycosides. Its bitter constituents, named "calicedrin" in West Africa, characterize the extract from the bark of K.senegalensis. It is used extensively as a bitter tonic for the treatment of a variety of pro-inflammatory disease [4].

\section{Materials and Methods}

\subsection{Preparation of Plant Materials}

Dried leaves and bark of the plant materials of K.senegalensis were collected directly from the field at January 2018. The plant parts were thoroughly washed and air dried and ground to powder. One hundred gram of powdered material of leaves and bark were extracted with $96 \%$ ethanol for 72 hours at room temperature. Extracts were first filtered through Whatman No. 4 filter paper. After filtration, the extracts were vacuum concentrated.

\subsection{Methods}

\subsubsection{Phytochemical Screening}

Qualitative preliminary phytochemical analysis was performed initially with different chemical reagents to detect the nature of phytoconstituents and their presence in plant parts. The presence of sterols/terpenes, flavonoids, tannins, alkaloids, lignins, saponins and cumarins were evaluated by standard qualitative methods $[5,6]$.

\subsubsection{Determination of Chemical Constituents of the Plant Extracts Using GC-MS}

The plant extracts were dissolved in ethanol (HPLC Grade) then the solution was transferred into the vial by syringe and micro-filter to avoid the presence of any particles not dissolved by the solvent, then the vial was inserted in the device. The qualitative and quantitative analysis of the sample was carried out by using GM/MS technique model (GC/MS-QP2010-Ultra) from japans 'Simadzu Company, with serial number $020525101565 \mathrm{SA}$ and capillary column (Rtx- $5 \mathrm{~ms}-30 \mathrm{~m} \times 0.25 \mathrm{~mm} \times 0.25 \mu \mathrm{m})$. The sample was injected by using split mode, helium as the carrier gas passed with flow rate $1.61 \mathrm{ml} / \mathrm{min}$, the temperature program was started from $60^{\circ} \mathrm{C}$ with rate $10^{\circ} \mathrm{C} / \mathrm{min}$ to $300^{\circ} \mathrm{C}$ as final temperature degree with 2 minutes hold time, the injection port temperature was $300^{\circ} \mathrm{C}$, the ion source temperature was $200^{\circ} \mathrm{C}$ and the interface temperature was $250^{\circ} \mathrm{C}$. The sample was analyzed by using scan mode in the range of $\mathrm{m} / \mathrm{z}$ 40-500 charges to ratio and the total run time was 26 minutes. Identification of components for the sample was achieved by comparing their retention times and mass fragmentation patterns with those available in the library, the National Institute of Standards and Technology (NIST)[7]..

\subsubsection{Antioxidant Activity}

The DPPH radical scavenging was determined according to the method of Shimada et al [8] with some modification. In 96-wells plate, the test samples were allowed to react with 2.2Di (4-tert-octylphenyl)-1-picryl-hydrazyl stable free radical (DPPH) for half an hour. The concentration of DPPH was kept as $(300 \mu \mathrm{l})$. The test samples were dissolved in DMSO while DPPH was prepared in ethanol. After incubation, decrease in absorbance was measured at $517 \mathrm{~nm}$ using Shimadzu Spectrophotometer UV double beam. Percentage radical scavenging activity by samples was determined in comparison with DMSO treated control group. Ascorbic acid was used as standard. The ability to scavenge the DPPH radical was calculated using the following equation: DPPH scavenging activity $(\%)=(\mathrm{A} 0-\mathrm{A} 1) / \mathrm{A} 0$ $\times 100$.

Where A0 is the absorbance of the control and A1 is the absorbance of the sample [9].

\section{Results and Discussions}

\subsection{Qualitative Preliminary Phytochemical Analysis}

Plants are composed of secondary metabolites which can be detected through phytochemical screening, which is the process of tracing these secondary metabolites in plants. Secondary metabolites are organic compounds which are not involved in the process of growth, development, reproduction of an organism, or other primary functions. Therefore in the absence of these compounds a plant will not die immediately, but will result in long term impairment in other functions, such as defensive mechanisms or aesthetic appearance, or in some cases of impact. Where a primary metabolites are necessary for functioning of the plant. Extracts of the plant were prepared using the powdered form and an appropriate solvent. The extract was then subjected to a range of chemical tests to detect the presence or absence of the secondary metabolites in the plant material. Qualitative preliminary phytochemical analysis was performed initially with different chemical reagents to detect the nature of phytoconstituents and their presence in bark and leaves extracts of K.senegalensis. Results of the presence of primary and secondary metabolites showed in Table 1. Phytochemical screening showed that the leaves and bark extracts were rich in chemical constituents. Both extracts contained phenolic compounds and fatty acids which are found to have antidiabetic activity. The results of chemical constituents of K.senegalensis extracts agree with that obtained by Elish et al. who reported that K.senegalensis contain secondary metabolites such as cumarins, tannins, compounds reducers, 
anthracenosides, flavonosids, carbohydrates, saponins, sterols, triterpenes, and cardiac glycosides [4]. The flavonoid was rich in leaves extract while it was not detected in bark, the biological function of flavonoid includes protection against allergies, inflammation, free radicals, platelet aggregation, microbes, ulcers, hepatotoxins and tumors [10]. These observations therefore support the use of K.senegalensis in herbal care remedies.

Other study approve that the plant K.senegalensis contains alkaloids which are ranked the most efficient therapeutically significant plant substance. Pure isolated plant alkaloids and their synthetic derivatives are used as a basic medicinal agent for their analgesic, antispasmodic and bactericidal effects. Specifically, saponins have been reported to have an antimicrobial effect and could serve as precursors of steroidal substances with a wide range of physiological activities [11].

Table 1. Preliminary phytochemical screening of leaf and bark extracts of k.senegalensis.

\begin{tabular}{|c|c|c|c|}
\hline \multirow[b]{2}{*}{ Test } & \multirow[t]{2}{*}{ Specific test } & \multicolumn{2}{|l|}{ Sample } \\
\hline & & Leaf extract & $\begin{array}{l}\text { Bark } \\
\text { extract }\end{array}$ \\
\hline \multirow{3}{*}{ Alkaloids } & Wagner's & -ve & -ve \\
\hline & Mayer's & $+\mathrm{ve}$ & -ve \\
\hline & Dragendroff's & $+\mathrm{ve}$ & $-v e$ \\
\hline \multirow{2}{*}{ Flavonoids } & Fecl3 & $+\mathrm{ve}$ & -ve \\
\hline & Lead acetate & $+\mathrm{ve}$ & -ve \\
\hline \multirow{2}{*}{ Sterols } & Salkowski & + ve & -ve \\
\hline & Libermann & $+\mathrm{ve}$ & $+\mathrm{ve}$ \\
\hline \multirow{2}{*}{ Triterpines } & Salkowski & $+\mathrm{ve}$ & -ve \\
\hline & Siberman & -ve & $+\mathrm{ve}$ \\
\hline \multirow{4}{*}{ Tannins } & $\mathrm{FeCl}_{3}$ & -ve & + ve \\
\hline & Gelatin & -ve & + ve \\
\hline & $\mathrm{HNO}_{3}$ & -ve & $+\mathrm{ve}$ \\
\hline & Lead acetate & -ve & $+\mathrm{ve}$ \\
\hline Saponins & Foam test & $+\mathrm{ve}$ & $+\mathrm{ve}$ \\
\hline Cumarins & UV test & -ve & $+\mathrm{ve}$ \\
\hline \multirow{2}{*}{ Glycosides } & kellrkiliani & $+\mathrm{ve}$ & $+\mathrm{ve}$ \\
\hline & kedd's & -ve & -ve \\
\hline Reducing sugar & Fehling's & $-\mathrm{ve}$ & -ve \\
\hline Anthraquinones & Ammonia test $25 \%$ & $-v e$ & -ve \\
\hline Lignins & Labat test & $-v e$ & $-v e$ \\
\hline Carbohydrates & Molish & $+\mathrm{ve}$ & + ve \\
\hline
\end{tabular}

The therapeutic effects of medicinal plants are attributed to the chemical constituents including: flavonoids, alkaloids, steroids, trepenoids, phenolic compounds, tannins, saponins and other compounds [12]. The results revealed the presence of saponin, flavonoid, tannin, alkaloid, glycoside and steroid. Similar studies by many researchers $[11,13,14]$ consistently reported phytochemical constituents of K.senegalensis to be alkaloids, tannins, saponins and flavonoids. Therefore the result of the phytochemical analysis of the crude extracts of K.senegalensis obtained in this study conforms to the previous reports. Other study by Kuta [15] who reported the phytochemical analysis of K.senegalensis revealed the presence of steroids, tannins, flavonoids, glycosides, saponins and alkaloids. Steroids and tannins were present in all parts of the plant. Flavonoids and glycosides were present in all parts with the exception of the aqueous leaf extract. Saponins and alkaloids were only present in the leaf extracts of both solvents.

\subsection{Chemical Composition of the Extracts Components Using GC/MS}

The present study was designed to obtain the phytochemical profile of Leaves and bark ethanolic extracts of K.senegalensis by GC-MS Table $2 \& 3$. The highest compound identified in both extracts represented the reducing sugar 4-O-Methyl mannose following the group of mannose sugar which are used in glycosylation is believed to be derived from glucose. Van de Venter [16] reported the mode of action as antidiabetic agent indicated the metabolic pathway through the digestion and absorption of carbohydrates.

Catechol is a phenolic compound which acts as antioxidant and the key mechanism of the chain-breaking action was attributed to hydrogen atom transfer from phenolic $\mathrm{OH}$ to the free radicals and it's presented in high percentage in leaves and barks extracts and they could be the reason for antioxidant activity of the plant and their antidiabetic performance [17].

Table 2. Chemical composition of leaves ethanol extract of khaya senegalensis using GC-MS.

\begin{tabular}{|c|c|c|c|}
\hline NO. & Name of Compound & Ret. Time & Area \% \\
\hline 1 & Benzyl chloride & 4.693 & 0.28 \\
\hline 2 & 4H-Pyran-4-one, 2,3-dihydro-3,5-dihydroxy-6-methyl- & 6.662 & 0.41 \\
\hline 3 & Catechol & 7.902 & 4.22 \\
\hline 4 & 2-Methoxy-4-vinylphenol & 9.105 & 1.10 \\
\hline 5 & Phenol, 2,6-dimethoxy & 9.621 & 1.05 \\
\hline 6 & Phenol, 2-chloro-5-methyl & 10.214 & 2.18 \\
\hline 7 & 1,3-Propanediol, 2-ethyl-2-(hydroxymethyl) & 10.908 & 4.66 \\
\hline 8 & beta.-D-Glucopyranose, 1,6-anhydro & 11.583 & 1.40 \\
\hline 9 & 2(4H)-Benzofuranone, 5,6,7,7a-tetrahydro-4,4,7a-trimethyl & 12.131 & 0.16 \\
\hline 10 & Ethyl iso-allocholate & 12.308 & 0.74 \\
\hline 11 & 4-O-Methylmannose & 13.814 & 14.73 \\
\hline 12 & 3,7,11,15-Tetramethyl-2-hexadecen-1-ol & 15.463 & 9.62 \\
\hline 13 & 2-Hexadecene, 3,7,11,15-tetramethyl & 15.535 & 0.76 \\
\hline 14 & 9-Eicosyne & 15.734 & 1.61 \\
\hline 15 & Phytol, acetate & 15.935 & 3.14 \\
\hline 16 & Albuterol & 16.412 & 0.90 \\
\hline
\end{tabular}




\begin{tabular}{llll}
\hline NO. & Name of Compound & Ret. Time & Area\% \\
\hline 17 & n-Hexadecanoic acid & 16.806 & 7.99 \\
18 & Hexadecanoic acid, ethyl ester & 17.094 & 2.69 \\
19 & Arabino-Hex-1-enitol, 1,5-anhydro-2-deoxy- & 17.415 & 3.01 \\
20 & Phytol & 18.334 & 4.70 \\
21 & $9,12,15$-Octadecatrienoic acid, (Z, Z, Z)- & 18.631 & 1.13 \\
22 & $9,12-$ Octadecadienoic acid (Z, Z)- & 18.786 & 1.45 \\
23 & Ethyl 9,12,15-octadecatrienoate & 18.860 & 1.60 \\
24 & Octadecanoic acid, ethyl ester & 19.042 & 1.14 \\
25 & Squalene & 24.346 & 14.53 \\
26 & gamma.-Tocopherol & 26.538 & 0.99 \\
27 & Vitamin E & 27.441 & 13.81 \\
\hline
\end{tabular}

Table 3. Chemical composition of bark ethanol extract of k.senegalensis using GC-MS.

\begin{tabular}{|c|c|c|c|}
\hline NO. & Name & Ret.Time & Area\% \\
\hline 1 & 4H-Pyran-4-one, 2,3-dihydro-3,5-dihydroxy-6-methyl- & 6.646 & 0.59 \\
\hline 2 & Catechol & 7.767 & 14.75 \\
\hline 3 & Phenol, 2,6-dimethoxy- & 9.610 & 0.44 \\
\hline 4 & trans-.alpha.-Bergamotene & 10.695 & 0.20 \\
\hline 5 & 1,3-Propanediol, 2-ethyl-2-(hydroxymethyl)- & 10.905 & 1.32 \\
\hline 6 & Bicyclo[4.1.0]heptane, 7-(1-methylethylidene)- & 10.957 & 0.53 \\
\hline 7 & D-Allose & 11.565 & 0.43 \\
\hline 8 & Homovanillyl alcohol & 12.146 & 0.81 \\
\hline 9 & Dodecanoic acid & 12.280 & 0.75 \\
\hline 10 & Phenol, 3,4,5-trimethoxy & 13.062 & 0.85 \\
\hline 11 & Levodopa & 13.376 & 6.82 \\
\hline 12 & 4-O-Methylmannose & 14.189 & 66.47 \\
\hline 13 & 2-Hydroxy-5-methylisophthalaldehyde & 15.692 & 0.46 \\
\hline 14 & n-Hexadecanoic acid & 16.800 & 2.39 \\
\hline 15 & Hexadecanoic acid, ethyl ester & 17.091 & 0.50 \\
\hline 16 & 9,12-Octadecadienoic acid $(\mathrm{Z}, \mathrm{Z})$ & 18.555 & 0.98 \\
\hline 18 & Oleic Acid & 18.586 & 0.43 \\
\hline 19 & (R)-(-)-14-Methyl-8-hexadecyn-1-ol & 18.783 & 0.84 \\
\hline 20 & Ethyl Oleate & 18.822 & 0.31 \\
\hline
\end{tabular}

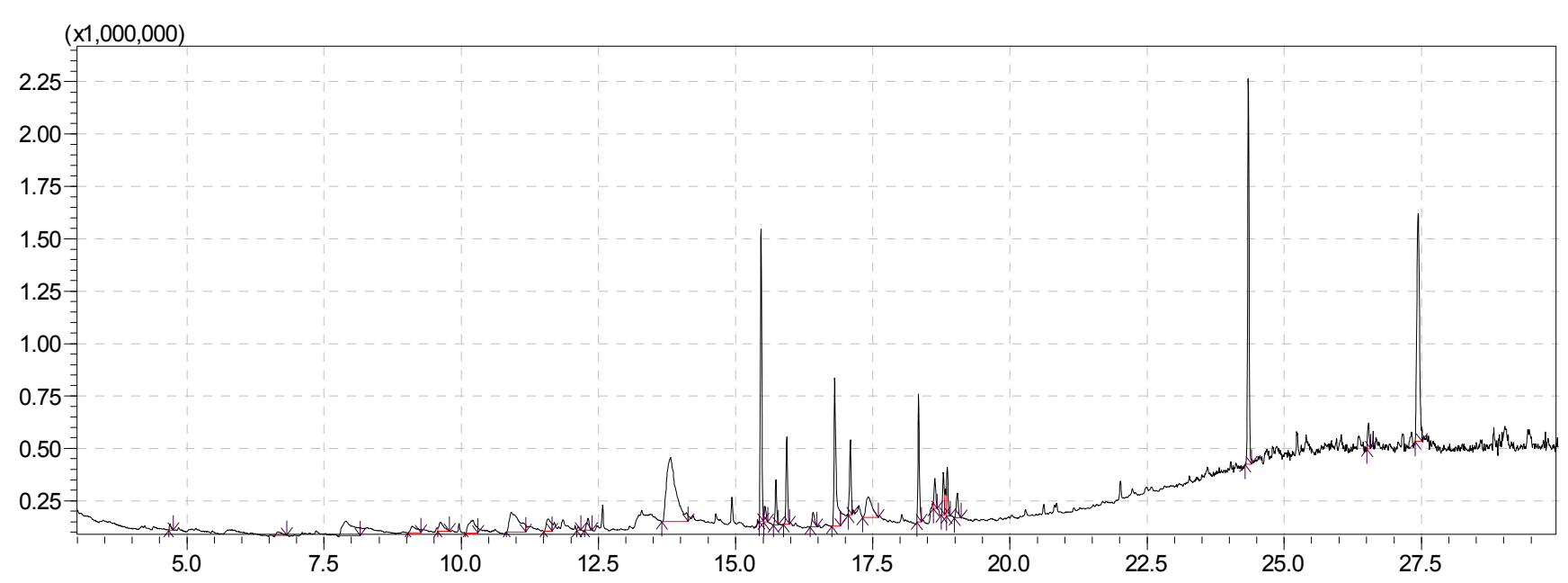

Figure 1. GC-MS chromatogram of leaves ethanol extract of $k$ senegalensis.

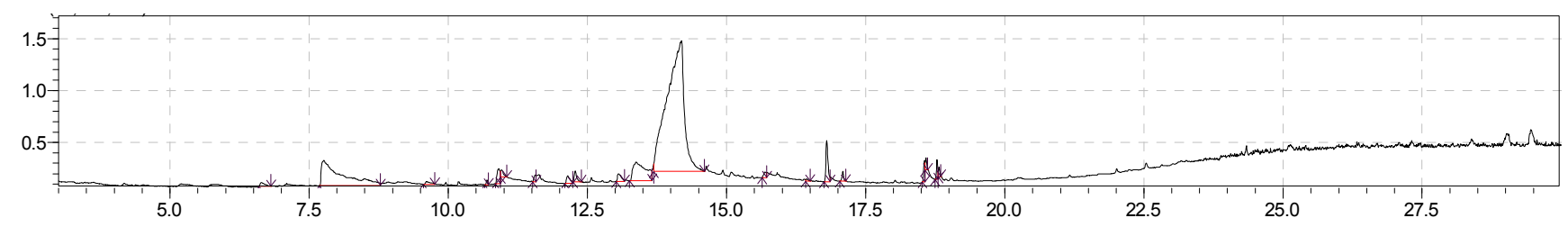

Figure 2. GC-MS chromatogram of bark ethanol extract of k.senegalensis. 
<smiles>Oc1ccccc1O</smiles><smiles>N[C@@H](Cc1ccc(O)c(O)c1)C(=O)O</smiles><smiles>C/C(=C\CO)CCC[C@H](C)CCC[C@H](C)CCCC(C)C</smiles>

Phytol<smiles>Cc1c(O)cc2c(c1C)O[C@](C)(CCC[C@H](C)CCC[C@H](C)CCCC(C)C)CC2</smiles>

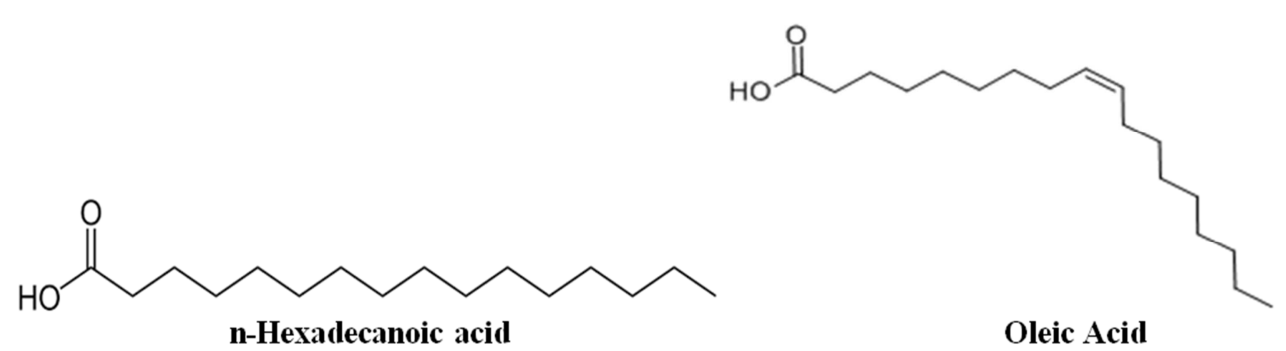

Figure 3. Chemical structure of compounds in leaves and bark extracts of K. senegalensis.

The utilization of this plant for traditional medicine by the people also predicted that the plant could have some bioactive ingredients. The present study was similar with that obtained by Aguoru [11] who reported the methanolic and aqueous extracts of stem bark of Khaya senegalensis had many chemicals identified using retention time, relative percentage of the compound, molecular weight and molecular formula included: pentadecanoic acid, nhexadecanoic acid, 9, 12-octadecadienoic acid, and 11octadecenoic acid. Others were 9-hexadecenoic acid, stearic acid, hexadecanoic acid, ricinoleic acid and 13-decosenoic acid. Some of these chemicals especially the acids have been demonstrated to be bioactive $[19,12]$.

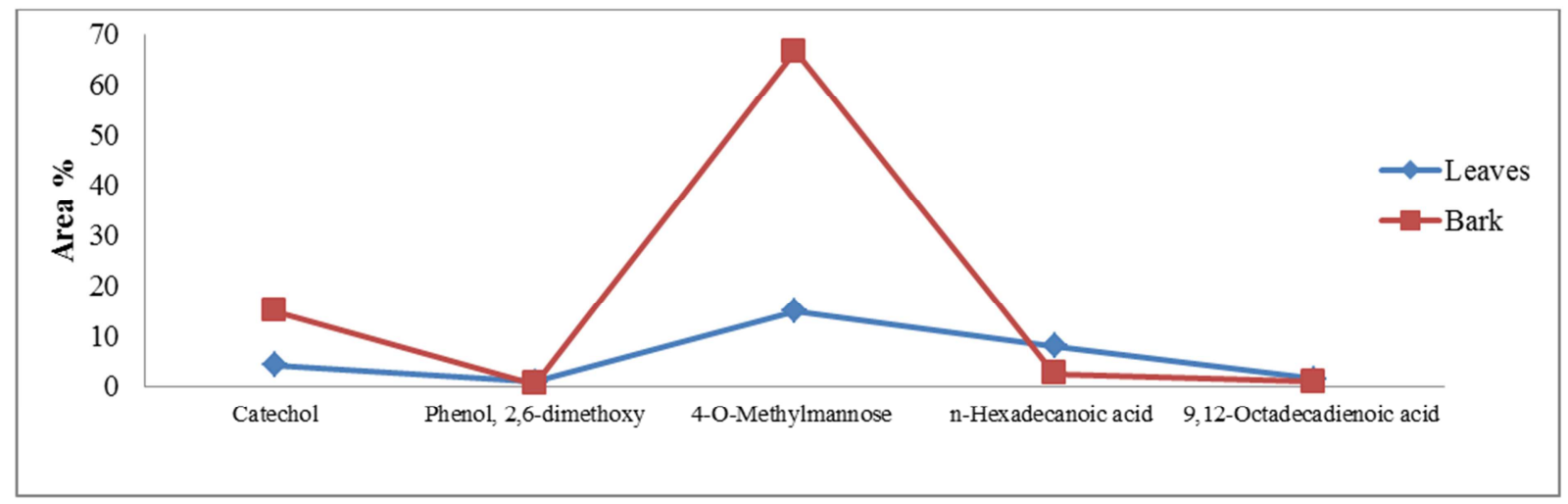

Figure 4. Comparison between similar components in leaves and bark extracts of K.senegalensis.

\subsection{DPPH Radical Scavenging Activity}

In-vitro antioxidant activity of the ethanolic extracts of leaves and bark from k.senegalensis was evaluated using DPPH assay; results are shown in Table 4. The in vitro antioxidant activity of the leaves and bark extracts of K.senegalensis was evaluated using DPPH assay. Results in Table 4 showed the highest result of antioxidant activity by DPPH scavenging assay in leaves extract (42.69\%) and lower 
result shown in bark extract (36.36\%). In comparison with ascorbic acid which gave $93.5 \%$ the leaves extract showed moderate activity but bark extract showed low activity. Previous study on K.senegalensis revealed that leaves and bark have potent antioxidant activity, the results agree with that obtained by Ibrahim who reported that the highest scavenging activity was observed with the ethanolic extract of the root then leaves followed by the bark aqueous extract [17]. The higher activity of leaves may be due to the presence of Vitamin $\mathrm{E}$ in this extract because it has free radical scavenging activity and present with high percentage of (13.81\%). Antioxidant capabilities and free radical scavenging properties are essential in using plant materials for curative purposes. The extracts from the three parts of the plant have exhibited antioxidant capabilities in comparison with the standard ascorbic acid [20].

Table 4. Antioxidant activity of leaves and bark extracts of k.senegalensis.

\begin{tabular}{ll}
\hline Sample & DPPH\% \\
\hline Leaves extract & 42.69 \\
Bark extract & 36.36 \\
Ascorbic acid (Standard) & 93.5 \\
\hline
\end{tabular}

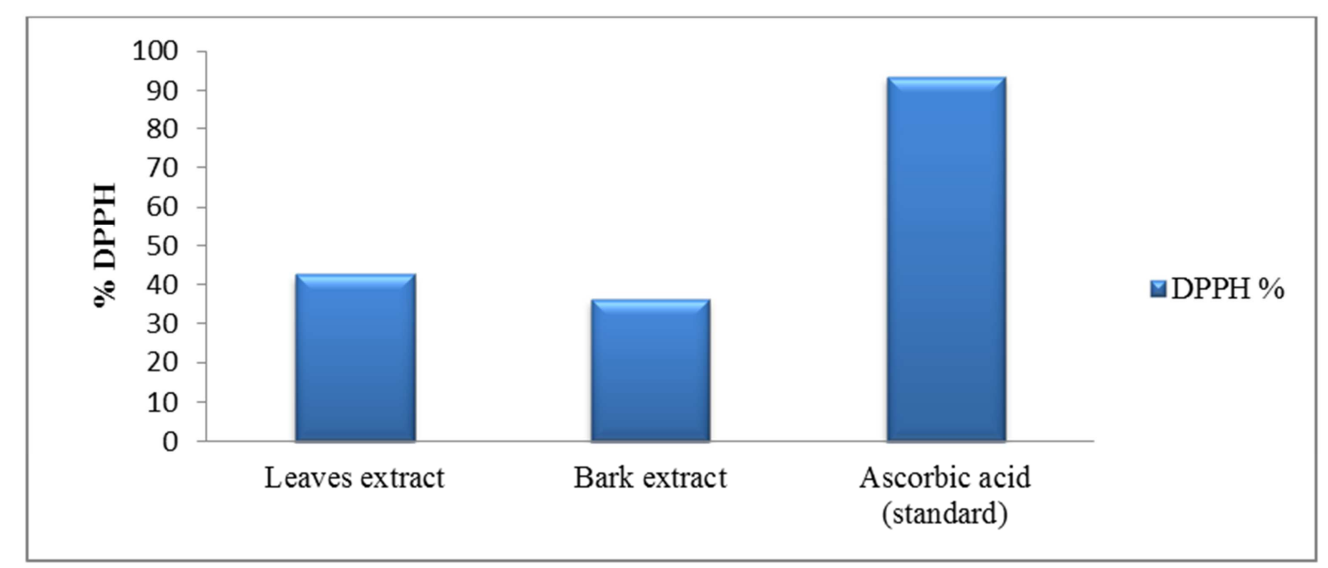

Figure 5. Comparison between DPPH scavenging activity of Ascorbic acid and K.senegalensis extracts.

\section{Conclusion}

Khaya senegalensis (African mahogany) is medicinally important and used for various purposes. Phytochemical screening showed that the leaves and bark ethanolic extracts were rich of chemical constituents, the presence of these secondary metabolites validate the use of the plant as herbal drug in Sudan. The study of chemical composition may possess significant bioactive compounds which contributed to the pronounced antioxidant and other biological activity.

\section{References}

[1] World Health Organization. Essential medicines and health products, Traditional and complementary medicine; 2014 Jun [cited 2016 Jul 3].

[2] Qazi, M and Molvi, K. Herbal Medicine. International Journal of Pharmaceutical Research; 2016. 8(2): 1-3.

[3] Xiao, m., Stephanie, j. et al. Chemopreventive Effects of Khaya senegalensis Bark Extract on Human Colorectal Cancer. Anticancer research. 2006; 26: 2397.

[4] Elisha, I. L., Makoshi, M. S., Makama, S., Dawurung, C. J., Offiah, N. V., Gotep, J. G., Oladipo, O. and Shamaki, D. Antidiarrheal evaluation of aqueous and ethanolic stem bark extracts of Khaya senegalensis A. Juss (Meliaceae) in albino rats. Pak. Vet. J., 2013; 33(1): 32-36.

[5] Trease, G. E., Evans, W. C. Textbook of Pharmacognosy. ${ }^{15}$ th
Ed.,2002. Saunders Publishers, London.

[6] Sood A, Kaur P, Gupta R (2012). Phytochemical screening and antimicrobial assay of various seeds extract of Cucurbitaceae family. Int. J. Appl. Bio. Pharm. Technol. 3(3):401-409.

[7] Alrasheid, A. A., Abdallah, B. S., Ali. A. O. (2018). In Vitro Antimicrobial Activity and GC-MS Analysis of Seed Extracts from Pimpinella anisum L. Journal of Drug Design and Medicinal Chemistry., 4( 2):16-21.

[8] Shimada, K., Fujikawa, K., Yahara, K. and Nakamura, T. Antioxidative properties of xanthan on the antioxidation of soybean oil in cyclodextrin emulsion. J Agric. Food Chem., 1992. 40:945-948.

[9] Braca A, Tommasi ND, Bari LD, Pizza C, Politi M, Morelli I (2001). Natural anti-oxidants from plant material in phenolic compounds in food and their effects on health. J. Nat. Prod., 64: 892-895.

[10] Okwu DE (2004). Phytochemicals and vitamins content of indigenous spices of South Eastern Nigeria. J. Sustain. Agric. Environ. 6:30-34.

[11] Aguoru, C. U., Bashayi, C. G and Ogbonna, I. O (2017). Phytochemical profile of stem bark extracts of Khaya senegalensisby Gas Chromatography-Mass Spectrometry (GC-MS) analysis. Journal of Pharmacognosy and Phytotherapy;9(3):35-43.

[12] Nyamai DW, Arika W, Ogola PE, Njagi ENN, Ngugi MP (2016). Medicinally important phytochemicals: An updated research avenue. Research and Reviews: J. Pharmacogn. Phytochem. 4(1):35-49. 
[13] Makut MD, Gyar SD, Pennap GRI, Anthony P (2007). Phytochemical screening and antimicrobial activity of the ethanolic and methanolic extracts of the leaf and bark of Khayasenegalensis. Afr. J. Biotechnol. 7(9):1216-1219.

[14] Wakirwa JH, Idris S, Madu SJ, Dibal M, Malgwi T (2013). Assessment of the In-vitro antimicrobial potential of Khaya senegalensi sethanol leaf extract. J. Chem. Pharm. Res. 5(7):182-186.

[15] Kuta, F. A., Tsado, D. J., Garba, S. A and Saidu, A. N (2015). Antibacterial activity of the leaf and stem bark crude extracts of Khaya senegalensis. Med. and Aromatic Plant Res. J., 3(1): 9-15. 2015.

[16] Van de Venter M, Roux S, Bungu LC, et al. Antidiabetic screening and scoring of 11plants traditionally used in South Africa. JEthnopharmacol2008; 119: 81-86.
[17] Ibrahim. M. A., Koorbanally, N. A and Islam, M. S. Antioxidative activity and inhibition of key enzymes linked to type 2 diabetes ( $\alpha$-glucosidase and $\alpha$-amylase) by Khaya senegalensis Records of Natural Products. 2013, 195-200.

[18] Wagner H., Pure Appl. Chem, 1990, 62-190.

[19] Shittu LAJ, Bankole MA, Ahmed T, Bankole MN, Shittu RK, Saalu CL, Ashiru OA (2007). Antibacterial and antifungal activities of essential oils of crude extracts of Sesame radiatum against some common pathogenic microorganisms. Iran J. Pharmacol. Ther. 6:165-170.

[20] Abalaka, M. E., Daniyan, S. Y., Akpor, O. B. and Inyinbor, A. A (2016). Antimicrobial, In-vitro Free Radical Scavenging, Antioxidant Properties of Leaf, Bark and Root Extracts from Khaya senegalensis. Journal of Microbiology Research, 1(1):54. 